$\infty$

0

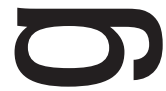

-

ת

1

$\longrightarrow$ 



\title{
UM TERRITÓRIO INDIFERENCIADO DOS SERTÕES: A GEOGRAFIA PRETÉRITA DO OESTE BAIANO (1501-1827)
}

\author{
AN INDIFFERENCIATED TERRITORY OF BACK COUNTRIES: THE PAST WEST BAIANO GEOGRAPHY (1501-1827) \\ UN TERRITÓRIO INDIFERENCIADO DE LA REGIÓN DE LOS “SERTÕES": LA GEOGRAFÍA PRETÉRITA DEL OESTE \\ BAHIANO (1501- 1827)
}

\author{
Paulo Roberto Baqueiro Brandão - Universidade Federal da Bahia \\ paulobaq@ufba.br
}

\begin{abstract}
Resumo
0 que se considera genericamente como Oeste Baiano - diferentemente da Região Econômica Oeste da Bahia - corresponde ao vasto território formado pelos municípios localizados na margem esquerda do Rio São Francisco, no domínio do cerrado. São, ao todo, trinta e cinco municípios que ocupam uma área de 183 mil km², correspondendo a um percentual pouco inferior aos $35 \%$ da extensão territorial do Estado da Bahia. Esta delimitação regional, absolutamente clara quando utilizada para designar os espaços de apropriação mais recente pelo poder estatal baiano, possui frágil assimilação identitária, o que suscita discussões as mais diversas sobre a pertinência do Oeste como região partícipe da dinâmica territorial do estado, já que, historicamente, foi considerado um espaço alheio à realidade cultural e econômica do restante da Bahia, estando pouco integrada, portanto. Neste sentido, o texto ora apresentado busca cumprir o objetivo de compreender, através do instrumental metodológico de análise pela via da longa duração, a formação territorial e socioeconômica da região antes chamada de "Além São Francisco" nos primeiros 326 anos de apropriação lusitana e brasileira.
\end{abstract}

Palavras-chaves: Dinâmica territorial. Geografia histórica. Oeste Baiano.

\begin{abstract}
What is generally considered as Baiano West - unlike the Economic West Region Bahia - is the vast territory formed by the counties located on the left bank of Rio São Francisco, in the cerrado.The are a total of thirty-five counties that cover an area of 183 thousand $\mathrm{km} 2$, corresponding to a percentage slightly lower than $35 \%$ of the territorial extension of the State of Bahia. This regional division is absolutely clear when used to designate the areas of most recent appropriation by the state of Bahia, it has a weak assimilation identity which leads to several discussions about the relevance of the west region as a participant of the dynamics of the territorial state, since historically, was considered an area outside the cultural and economic reality of the rest of Bahia, being little integrated so. In this sense, the text presented meet the objective of seeking understanding through the instrumental methods of analysis by long duration, the training area and the socioeconomic regions before called "Beyond San Francisco" in the first 326 years of Lusitanian and Brazilian ownership.
\end{abstract}

Key-words: Territorial dynamics. Historical geography. Baiano West.

\section{Resumen}

Lo que se considera genéricamente como Oeste Bahiano - diferentemente de la región económica Oeste de la Bahia corresponde al vasto território formado por los municípios localizados en la margen izquierda del rio São Francisco, en el domínio del cerrado. Son ,en total, treinta y cinco municípios que ocupan una área de $183 \mathrm{mil} \mathrm{km}^{2}$, correspondiendo a un porcentaje un poco menor a los 35\% de la extensión territorial del Estado de la Bahia. Ésta delimitación regional, absolutamente clara cuando es utilizada para designar los espacios de apropiación más recientes por el Poder Estatal Bahiano, posúe frágil asimilación identitária, lo que suscita discuciones de las más diversas sobre la pertinencia del

\begin{tabular}{|l|c|c|c|c|c|c|}
\hline Boletim Goiano de Geografia & Goiânia - Goiás - Brasil & v. 29 & n. 1 & p. 47-56 & jan. / jun. & 2009 \\
\hline
\end{tabular}


Oeste como región partícipe de la dinámica territorial del Estado, ya que, históricamente, fue considerado un espacio ajeno a la realidad cultural y económica del resto de la Bahia, estando poco integrada, por lo tanto. En este sentido, el texto ora presentado busca cumplir el objetivo de comprender, a traves del instrumental metodológico del análisis por la via de larga duración, la formación territorial y socioeconómica de la región antes llamada "Além São Francisco" en los primeros 326 años de apropiación Lusitana y Brasileña.

Palabras clave: Dinámica territorial. Geografía histórica. Oeste bahiano.

\section{Introdução}

Os termos Região Oeste da Bahia e Oeste Baiano não devem guardar equivalência conceitual. Se o primeiro, com seus 22 municípios constantes, faz referência a uma das regiões componentes da divisão econômica do estado, como o querem organismos estatais do quilate do Instituto Brasileiro de Geografia e Estatísticas e da Superintendência de Estudos Econômicos e Sociais da Bahia, o segundo designa todo o território à esquerda do Rio São Francisco, onde estão localizados 35 municípios baianos, em uma área de pouco mais de 183 mil km².

$\mathrm{O}$ escrito que segue se destina a compreender os principais aspectos referentes à formação territorial e socioeconômica desta segunda entidade geográfica, que corresponde ao espaço reivindicado por grupos sociais e econômicos ali estabelecidos para a formação do Estado do São Francisco, utilizando para tal um método de análise próprio da Geografia Histórica.

Para tanto, é imprescindível a adoção de uma linha de raciocínio que permita compreender a construção do território oestino como um processo histórico. Assim, a periodização se converte em um recurso fundamental na análise geográfica pela via da longa duração.

Neste sentido, tempo e espaço, considerados como categorias equivalentes e não apenas simultâneas, são tomados como uma totalidade prenhe de relações sociais que se estabelecem em acordo com grandes eventos, cujas repercussões adquirem escala mundial/internacional, mas também por outros, cujo sentido e significado são percebidos apenas em determinado lugar ou região. Daí surgirem diferentes formações espaciais ligadas a temporalidades próprias daquele lugar que as abriga.

Quando novas práticas tomam lugar na história, porém, há uma ruptura na ordem estabelecida, impondo mudanças políticas, sociais, econômicas e culturais, produzindo reflexos na modelagem do espaço abordado. Tal ruptura seria um “período denso” (VASCONCELOS, 1999, p. 191) ou, em outras palavras, um rompimento no processo histórico vigente que dá início a um novo quadro da realidade nas suas diversas dimensões. 
Assim, em cada lapso temporal delimitado por esses ditos períodos densos, deve-se analisar, além dos eventos significativos, o papel dos agentes de produção do espaço e as transformações e permanências que se pode verificar no território a partir da atuação dessas forças, revelando as espacialidades próprias de cada momento da história que, neste caso, diz respeito ao Oeste Baiano.

Deste modo, o período em exame, denominado O oeste do São Francisco: território indiferenciado dos Sertões, corresponde ao interstício entre o ano de 1501, quando da descoberta da foz do Rio São Francisco por André Gonçalves e Américo Vespúcio, dada a importância da via fluvial no povoamento das terras interioranas durante o Brasil Colônia, e 1827, momento em que o governo imperial brasileiro determina a anexação da margem esquerda daquele curso d'água, então denominadas de Comarca do São Francisco, pela Província da Bahia em detrimento de Pernambuco, como represália aos atos decorrentes da formação da Confederação do Equador.

Tal temporalidade corresponderia, grosso modo, a um período natural do Oeste Baiano, dada a marcada presença da natureza no transcorrer da vida nos esparsos ecúmenos ali edificados, como se verá a seguir.

\section{0 oeste do São Francisco: território indiferenciado dos sertões (1501-1827)}

O exame do processo de construção do território que hoje se convencionou chamar de Oeste Baiano, no período colonial não deve prescindir da compreensão de um fato que o antecede, mas sem o qual a formação de ecúmenos não indígenas naquelas terras provavelmente seria retardada em alguns anos: a descoberta da foz do Rio São Francisco, durante expedição comandada por André Gonçalves e Américo Vespúcio, em 04 de outubro de 1501, dia dedicado ao santo que lhe dá nome. Daí a opção por conceber aquele ano como início desta análise.

O final do período - 1827 - é marcado, por sua vez, pela incorporação do território então conhecido como Comarca do São Francisco à Província da Bahia, através da sua perda por Pernambuco, como represália do Império do Brasil à Confederação do Equador. Não antes, porém, de ter sido anexado à Província de Minas Gerais durante cerca de três anos.

A longevidade de 326 anos se explica pela perpetuação de processos econômicos, sociais e políticos que não foram capazes de produzir transformações significativas ao ponto de gerar um novo quadro na formação do território ao longo deste lapso de tempo. 
A formação do território oestino neste período seguiu o curso lento da apropriação da natureza pelo homem em consonância com a conformação daquilo que Santos (2004) chamou de Meio Natural. Naquele momento, a produção estava associada à oferta da Natureza, sem imposições das técnicas sobre o ritmo da vida.

A sociedade que se formou no atual Oeste Baiano entre os anos de 1501 e 1827 - e, como consequência, o território daí gestado - era, pois, o resultado de um modo de produção que obtinha dos componentes naturais do sertão tudo o que era necessário, sem a introdução de técnicas genuinamente capazes de produzir grandes transformações de caráter socioespacial.

\section{O contexto socioespacial e os principais agentes do período}

Como afirmado por Rêgo (1945), o interior do Brasil é uma região em cuja formação pretérita se pode observar isenção quase absoluta de influências externas. Neste sentido, a análise do contexto socioespacial desse fragmento do atual território baiano, ao menos nos primeiros séculos de colonização, possui alinhamentos mais consistentes com fenômenos que tenham rebatimentos de âmbito colonial, regional e, por vezes, local, mas quase nunca com fatos de importância internacional/mundial, diferentemente do que ocorrera nas terras do litoral, cujas estruturas econômicas, sociais, políticas e culturais eram francamente sensíveis aos acontecimentos externos.

O atual Oeste Baiano não possuía qualquer sustentação histórica que o diferenciasse em relação ao conjunto do sertão (FREITAS, 1999). Assim, entre o século XVI e início do XIX, a “conquista” do Oeste resultou da própria interiorização da economia colonial/imperial, notadamente através da busca de novos espaços para a atividade agropecuária e exploração de minerais e pedras preciosas.

O marco de abertura desse processo de ocupação foi o ano de 1534, quando a Coroa Portuguesa, através da Carta de Évora, concedeu à Capitânia de Pernambuco o direito de posse das terras localizadas na margem esquerda do Rio São Francisco.

Ainda assim, ao longo dos séculos XVI e XVII, coube àqueles agentes que habitavam a Capitania da Bahia a primazia de empreender os esforços de inserção do atual Oeste Baiano à realidade econômica da colônia. Se as terras a oeste do São Francisco pertenciam por direito à Capitania de Pernambuco, elas foram apropriadas de fato pelos baianos, menos atribulados 
com a defesa do litoral que os donatários de Olinda e, portanto, com maior disponibilidade de homens, armas e dinheiro para adentrar o grande sertão.

Já nos primeiros anos da apropriação espacial portuguesa na América, dois foram os caminhos preferenciais que permitiram o acesso de exploradores ao interior da colônia: o Rio São Francisco, descoberto em 1501, e as estradas abertas desde Salvador e Olinda rumo ao Sertão de Dentro e ao Sertão de Fora, designações dadas às terras sertanejas da Bahia e de Pernambuco e Piauí, respectivamente. Em ambos os casos, a formação de percursos direcionados às terras distantes do litoral esteve associada à produção econômica que se quis empreender no sertão nordestino: a exploração da pecuária, como observado por Andrade (2004; 2006).

Assim, exploradores saídos especialmente de Salvador, mas também de Olinda, eram enviados sob ordem de importantes detentores de sesmarias e, com os auspícios do Governo-Geral (PIERSON, 1972), expulsaram os índios e estenderam a produção de alimentos diversos, mas principalmente a pecuária, até as margens do Rio São Francisco, tendo sido decisivos na criação de pequenas nucleações que davam certo apoio à manutenção das atividades (BAHIA, 2000).

Se durante o século XVI, a formação dos ecúmenos ainda era tímida, ao longo do século seguinte os grandes latifúndios originários das sesmarias de famílias tradicionais, como Garcia D’Ávila e Guedes de Britto (ROCHA, 1940), foram responsáveis pela maior incidência de currais nas margens do Rio São Francisco e, em seguida, nos cursos navegáveis dos rios Grande, Corrente e Preto.

Além do Estado Português, dos agentes econômicos e da ainda escassa população em busca de ganhos, a Igreja, embora timidamente, teve o seu papel como agente de produção do espaço no atual Oeste Baiano: quando da formação das primeiras fazendas no encontro dos rios Grande e São Francisco pelos proprietários da Casa da Torre entre os anos de 1670 e 1680, monges franciscanos ergueram a Capela de São Francisco das Chagas da Barra do Rio Grande, criando um aldeamento de índios catequizados (PIERSON, 1972); em 1706, padres capuchinhos fundaram a Missão do Aricobé, entregue posteriormente aos franciscanos (ALMEIDA, 2005). Este estabelecimento teve a função de catequizar os índios aricobés, único grupo remanescente dos habitantes pré-colombianos ainda existente no Oeste Baiano.

Por outro lado, segundo Andrade (2004), a criação de gado estava também associada à produção mineradora, introduzida no Brasil em grande escala a partir do século XVIII. Levando-se em conta que o atual Oeste Baiano está 
localizado, grosso modo, entre as frentes de produção mineradora de Minas Gerais, Goiás e da Chapada Diamantina/Jacobina, não é difícil inferir que a assertiva de Andrade (2004) se aplique, entre outras, às terras em exame.

O primeiro terço do século XIX foi um período no qual os agentes de produção do espaço regional - o Estado, os agentes econômicos, a sociedade civil e a Igreja - atuaram muito mais no sentido de garantir permanências em relação à dinâmica socioeconômica advinda de séculos anteriores. Assim, a grande transformação que se viu na região foi de ordem política, mas com rebatimento decisivo na dinâmica territorial, como se verá a seguir.

Os fatos que culminaram no episódio conhecido como Independência da Bahia (02 de julho de 1823) pouco repercutiram no atual Oeste Baiano, seja porque, naquele momento, essas terras eram parte do território da Província de Pernambuco, seja pela limitação quase que total dos confrontos no Recôncavo Baiano (TAVARES, 2001), muito embora, segundo Rocha (1940), vaqueiros do Sertão tenham sido arregimentados para as frentes de batalha. Por outro lado, um fato que sucedeu a Independência do Brasil, ocorrida menos de um ano antes das lutas na Bahia, teve repercussão crucial para os destinos do Oeste.

Em 1824, por decisão do recém instalado governo imperial brasileiro, a então Comarca de São Francisco passou a figurar como parte do território provincial mineiro, tendo sido desmembrado de Pernambuco como uma resposta do Império ao posicionamento de setores da sociedade civil e eclesiástica daquela província contrários à monarquia, o que culminou na formação da Confederação do Equador. Três anos depois, em 1827, a decisão foi revista e a Comarca do São Francisco passou a pertencer à Província da Bahia (ALMEIDA, 2005).

\section{Dinâmica territorial}

Durante os anos de 1501 a 1827, a incorporação das terras à esquerda do Rio São Francisco à realidade colonial brasileira se deu de forma lenta, produzindo territorialidades assentadas, quase sempre, no interesse econômico dos agentes de produção daquele espaço regional, cujas atividades agropecuárias, extrativas e comerciais não exigiam grandes contingentes populacionais e tampouco técnicas de manufatura das mais elaboradas.

Do mesmo modo, nos primeiros dois séculos e meio de colonização, dado o caráter extensivo da pecuária, a formação dos insipientes assentamentos "pro- 
tourbanos" esteve ligada muito mais à necessidade de criação de pequenos entrepostos comerciais que a uma vigorosa economia e sociedade citadinas, como rapidamente se viu tanto no Recôncavo Baiano, quanto no eixo Olinda-Recife.

Assim, apenas em 1752, foi criada, por Resolução Regia (BAHIA, 1936), a primeira nucleação com status de vila do Oeste Baiano, denominada Vila de São Francisco das Chagas da Barra do Rio Grande do Sul (atual Barra), construída como uma espécie de cabeça-de-ponte do governo colonial, garantindo a presença do Estado Português naquela vastidão sertaneja, onde ainda existiam confrontos entre fazendeiros e índios.

A segunda vila estabelecida no período, a de Pilão Arcado, ascendeu a esta condição apenas em 1810, através do Alvará de 15 de janeiro daquele ano (BAHIA, 1936). Ambas as vilas estavam, quando nomeadas, sob jurisprudência da Província de Pernambuco.

Assim, entre os municípios que existem atualmente no Oeste Baiano, os de Barra e Pilão Arcado são considerados originários, ou seja, são municípios "para os quais não há qualquer tipo de documento ou análise que estabeleça ou evidencie relação de cunho territorial ou administrativo entre o município criado e qualquer outro" (SÃO PAULO, 1995, p. 59). Em outras palavras, são municipalidades surgidas sem que tenham sido por desmembramento de uma outra.

Antes, porém, alguns arraiais já tinham sido edificados no transcorrer do século XVII, com relativa concentração de comércio e serviços, além da organização de milícias para o enfrentamento dos índios. São os casos da já citada localidade de Pilão Arcado Santa Rita do Rio Preto (atual Santa Rita de Cássia) e Campo Largo, atual distrito de Taguá, município de Cotegipe (ALMEIDA, 2005), que em 1820 ascendeu à condição de vila, desmembrada de Barra (BAHIA, 2001).

Diferente do que ocorrera no Recôncavo Baiano, região a qual Santos (2005) reputou a condição de ter sido a primeira rede urbana das Américas, no Oeste, não houve grande profusão de relações reticuladas entre os núcleos surgidos até, pelo menos, o final do século XVIII, já que, por um lado, quase não havia abastecimento entre os assentamentos, e sim, entre estes e as fazendas e minas; por outra parte, tais caminhos eram formadores de grandes percursos lineares, quase sem pontos de interseção entre si. De qualquer modo, é importante frisar que, no caso oestino, localidades como as atuais Pilão Arcado, Barra e Carinhanha foram importantes entrepostos comerciais entre a Bahia e Piauí/Maranhão, Goiás e Minas Gerais, respectivamente (ROCHA, 1940; RÊGO, 1945; PIERSON, 1972). 
A inexistência de uma consolidada rede urbana oestina nos primeiros séculos da presença portuguesa na América, não permite desconsiderar, porém, a importância dos caminhos como meio de contato entre as esparsas comunidades que se formavam nas suas margens, bem como entre o sertão e a urbanidade existente no litoral.

Alguns desses caminhos tinham no transporte de pedras e metais preciosos, para os portos litorâneos, a sua razão de ser, como no caso da atual BR-242 que, segundo Teixeira Neto (2001), corresponde praticamente ao mesmo traçado da antiga estrada colonial da Bahia.

Desta forma, é possível afirmar que a constituição do território oestino no período entre os anos de 1501 e 1827, se deu de forma linear mais do que areal, já que o povoamento e as atividades econômicas obedeciam aos caminhos fluviais e terrestres que eram abertos. Assim, os principais ecúmenos estavam situados na margem esquerda do Rio São Francisco ou em ambas as margens dos seus principais tributários, como os rios Grande, Corrente e Preto, bem como ao longo das estradas que permitiam atingir a Bahia litorânea, Minas Gerais, Goiás, Piauí/Maranhão.

\section{Considerações finais}

Este escrito, um exercício de aplicação em âmbito regional do método de análise desenvolvido por Vasconcelos (1999) para estudos de Geografia Histórica realizados em escala urbana, buscou compreender a história do território que atualmente se convencionou chamar de Oeste Baiano no período entre os anos de 1501, momento da descoberta da foz do Rio São Francisco, e 1827, quando da anexação daquelas terras à Província da Bahia.

Esta temporalidade converge, grosso modo, com a da constituição do meio natural no Oeste Baiano, já que as divisões social e territorial do trabalho vigentes na época resultavam "da combinação entre as necessidades de cada produto e as condições naturais preexistentes" (SANTOS e SILVEIRA, 2001, p. 30), não havendo, portanto, uma imposição do homem sobre os ritmos lentos da natureza.

Se nos dias atuais, o Oeste Baiano é considerado uma das mais importantes regiões agroindustriais do Brasil, e o vigoroso crescimento recente da população urbana é revelador das grandes transformações socioespaciais ocorridas nos últimos trinta anos naquele vasto território à esquerda do Rio 
São Francisco, o mesmo não se pode afirmar quando este mesmo tratamento analítico se aplica ao seu passado.

Nos primeiros três séculos da presença lusitana e brasileira na região, não era possível diferenciá-la do restante do território que se estendia para além do litoral, já que, por suas características socioespaciais e geoeconômicas, o atual Oeste formava uma continuidade indiferenciada do que, à época, se convencionou chamar de sertão.

A atividade pecuária extensiva, a pequena agricultura, o trânsito de minérios e o comércio tímido, porém importante para as populações locais, foram os responsáveis principais pela existência de esparsos assentamentos humanos e caminhos que funcionavam como alternativa à navegação, não sendo capazes, porém, de fundar uma vigorosa articulação reticular, como ocorrera no Recôncavo Baiano já no início da colonização portuguesa, o que pesou na manutenção de um quadro da realidade oestina que só viria sofrer transformações significativas no findar do primeiro terço do século XIX.

\section{Referências}

ALMEIDA, Ignez Pitta. Barreiras, uma história de sucesso. Barreiras: Cangraf Editora, 2005. ANDRADE, Manuel Correia de. A questão do território no Brasil. São Paulo: Hucitec, 2004. 2006. . Formação territorial e econômica do Brasil. Recife: Fundação Joaquim Nabuco,

BAHIA, Estado da. Anuário Estatístico da Bahia. Ano de 1934. Salvador: Graphica Oficial, 1936.

Mudanças sociodemográficas recentes. Oeste. Salvador: Superintendência de Estudo Econômicos e Sociais da Bahia, 2000.

. Evolução territorial e administrativa do Estado da Bahia: um breve histórico. Salvador: Superintendência de Estudos Econômicos e Sociais, 2001.

FREITAS, Antonio Fernando Guerreiro de. Oeste da Bahia: formação histórico-cultural (primeira parte). Cadernos do CEAS, Salvador, n. 181, pp. 59-78, 1999.

MIRANDA, Agenor Augusto de. O Rio São Francisco. Como base do desenvolvimento econômico do nosso interior. São Paulo: Companhia Editora Nacional, 1941.

PIERSON, Donald. O homem no vale do São Francisco. Tomo I. Rio de Janeiro: Ministério do Interior, 1972.

ROCHA, Geraldo. O rio de São Francisco. Factor precipuo da existência do Brasil. São Paulo: Companhia Editora Nacional, 1940. 
RÊGO, Luís Flores de Morais. O Vale do São Francisco. São Paulo: Renascença, 1945.

SANTOS, Milton. A urbanização brasileira. São Paulo: Editora da Universidade de São Paulo, 2005.

A natureza do espaço. Técnica e tempo, razão e emoção. São Paulo: Editora da Universidade de São Paulo, 2004.

SANTOS, Milton e SILVEIRA, María Laura. O Brasil. Território e sociedade no início do século XXI. Rio de Janeiro: Record, 2001.

SÃO PAULO, Estado de. Quadro do desmembramento territorial e administrativo dos municípios paulistas. São Paulo: Instituto Geográfico e Cartográfico, 1995.

TAVARES, Luís Henrique Dias. História da Bahia. Salvador: Editora da Universidade Federal da Bahia, 2001.

TEIXEIRA NETO, Antônio. Os caminhos de ontem e de hoje em direção a Goiás-Tocantins. Boletim Goiano de Geografia. Goiânia, v. 1, n. 21, pp. 51-68, 2001.

VACONCELOS, Pedro de A. Questões metodológicas na Geografia Urbana Histórica. In: VASCONCELOS, P. e SILVA, S. (org). Novos estudos de Geografia Urbana brasileira. Salvador: Editora da Universidade Federal da Bahia, 1999, pp. 191-201.

Paulo Roberto Baqueiro Brandão - Doutorando do Programa de Pós-graduação em Geografia da Universidade Federal de Pernambuco, Professor Assistente do Curso de Geografia da Universidade Federal da Bahia.

Recebido para publicação em Abril de 2009 Aceito para publicação em Maio de 2009 